\title{
Genetic Polymorphism
}

National Cancer Institute

\section{Source}

National Cancer Institute. Genetic Polymorphism. NCI Thesaurus. Code C17004.

The regular and simultaneous occurrence of alternative nucleotide sequences at equivalent locations of the genetic material among individuals of a single interbreeding population that are not maintained by recurrent mutation. Polymorphisms may range in size from single nucleotide to large nucleotide sequence variation visible at the chromosomal level. 